\title{
New Product Development During the Last Ten Years: The Ongoing Debate and Future Avenues
}

Giacomo Marzi - University of Lincoln, UK (ORCID: 0000-0002-8769-2462)

Francesco Ciampi - University of Florence, IT (ORCID: 0000-0002-2217-3872)

Daniele Dalli - University of Florence, IT (ORCID: 0000-0002-7909-0963)

Marina Dabic - University of Zagreb \& Nottingham Trent University, HR UK

(ORCID: 0000-0001-8374-9719)

\section{Published on IEEE Transactions on Engineering Management}

\section{FULL TEXT (DOI): $\underline{\text { http://doi.org/10.1109/TEM.2020.2997386 }}$}

Index Keywords: New Product Development, New Service Development, NPD, NSD, StageGate, Agile, Open Innovation, SMEs, Family Firms, Cross-functional Integration, CFI, Market Orientation, Dynamic Capabilities, Strategic Alliances, Lead Users, Co-Creation, Supply Chain Integration, Literature Review, Bibliometrics, VOSviewer

\begin{abstract}
Research on new product development (NPD) has grown considerably over the last 30 years interweaving with serval fields of study such as strategy, marketing, supply chain management, and project management. This study offers an overview of the development of the NPD management literature published over the last ten years (2008 to 2018) in 1,226 peer-reviewed articles. By applying bibliometric analysis, we have discovered the existence of five research clusters focused on the following main thematic areas: the NPD process, the integration of diverse knowledge sources for NPD optimization, the relationship between NPD and corporate strategy, the role of users and consumers in the NPD process, the supplier involvement in the NPD activities. In respect of each area, we selected and reviewed the most relevant contributions and presented the emerging theoretical approaches and best practices. Also, the analysis has helped us to uncover the existence of promising research areas that have been scarcely explored. As a result, we formulated some suggestions for further research to fill in the existing gaps.
\end{abstract}




\section{Managerial Relevance Statement}

This paper sheds light on the latest developments in the NPD literature. We provide managers and professionals with a selection of the leading research trends, issues, and approaches proposed by scholars and practitioners in the last ten years. For each of the five identified thematic areas, we provide a guide to understanding and interpreting the emerging best practices with a focus on the importance of the cross-functional knowledge integration, the role of market orientation, the relevance of the intertwining between NPD and the company's strategy, and finally the pivotal role of suppliers in creating a superior NPD process' performance. Also, we propose a research agenda for NPD future research composed of a series of wide-spanning research questions. We hope that this agenda can help not only researchers to unpack the proposed questions in specific pieces of research but also practitioners to reflect on the emerging research themes and translate them in new managerial practices.

\section{Introduction}

Research on new product development (NPD) has grown exponentially over the last 30 years, making this topic an autonomous and established field of research, ranging from management to engineering [1]-[3]. Over the years, NPD research and practice have changed a great deal, as the various surveys on NPD best practices, which the Product Development \& Management Association (PDMA) sponsored showed [4]-[7]. During the last ten years, NPD research has been intertwined with other research areas, such as Strategy and Strategic Management, Marketing, Consumer Behavior, Organizational Studies, and Supply Chain Management. Studies dealing with alliances [8], [9], competition [10], and dynamic capabilities [11] recognized the NPD process as a critical element in defining companies' strategic positioning. On the other hand, marketing studies highlighted the importance of users' involvement in the NPD process's various stages [12], focusing on how users can increase new products' performance and time to market [13], and how brand communities can provide new ideas for NPD processes [14]. As a result, while the interest in NPD related studies has increased over time, the NPD literature has dramatically evolved into a multidisciplinary direction by integrating diverse sources of practitioners' insights and academic studies. From 2000 onward, several literature reviews have shown the increasing importance of the interconnection between engineering and management for the NDP research and highlighted that NPD should be considered as a vital element of the company strategy [1]-[3]. Furthermore, many emerging engineering issues, such as the increasing need for flexibility and the constant pressure for NPD's cost reduction, are heavily impacting on the strategic, marketing, and operational choices made by managers. As a result, on the one hand, an increasing number of management scholars consider today NPD a key element in their studies; on the other hand, engineering management journals are increasingly paying attention to NPD managerial issues [15]. Based on these considerations, along with the absence of a recently available literature review of the field [1]-[3], the present study focuses on the latest developments of the NPD research carried out in the field of business and management from 2008 to 2018. 
Our analysis identified five areas of NPD literature research: the NPD process and its best practices, the integration of different sources of knowledge and information for NPD optimization, the relationship between NPD and corporate strategy, the role of users in the NPD process, the supplier involvement in the NPD activities.

The study is structured as follows: in the next section, we describe the methodology, after which we present the bibliometric analysis's results, the VOS analysis, and the literature review of the five research areas. Section five proposes an agenda for future NPD research, while section six concludes the paper and describes its limitations.

\section{Methods}

Our literature review is based on a bibliometric analysis of the bibliometric activity indicators [16] and the visualization of similarities (VOS) [17]. This method has been widely used across multiple study fields, demonstrating its effectiveness in synthesizing and representing high volumes of bibliographic data [15], [18], [19]. We developed a five-step process to explore NPD scientific production and present the results.

As a first step, in early January 2019, we started a review of NPD papers in order to have an updated overview of the topic and create a list of the key terms used in this area of study. After several iterations with additional keywords and in line with the suggestions coming from previous literature reviews in the field [1]-[3], we identified the two following terms that permitted us to retrieve all the relevant material for the present study: "new product development" and "npd". After that, we searched the two terms in the Web of Science Core Collection database [20], [21] by applying the operator "TS" which searches for titles, abstracts, and keywords, as follows: "TS=("new product development") OR TS=(npd)." Furthermore, following previous literature reviews [1]-[3] and best practices [20], we limited the search documents published in English and to the "articles" category in order to include only high-quality material that had undergone a double-blind peer-review process. In line with the purpose of our study, we only considered articles between 2008 and 2018 in the Web Of Science's categories of "business" and "management." The query produced 1,315 documents. A cross-validation of the results made by using Scopus and EBSCO databases did not show any significant discrepancy with the Web Of Science's data.

Next, we started the core phase of our bibliometric study by using VOS viewer 1.6.10, where we carried out a VOS analysis based on the bibliographic coupling aggregation mechanism [17]. Bibliographic coupling occurs when two papers cite the same third paper in their references. We decided to use bibliographic coupling due to its ability to identify the development of a given field's intellectual structure by highlighting the main theoretical approaches and the relationships between them [22]. The graphical output of the VOS analysis emerges from a routine that builds a similarity matrix by normalizing a co-occurrences matrix of items; in this case, the shared cited references [23]. The script performs a set of routines to build a two-dimensional map in which the items are positioned to represent their similarity in terms of cited references. In the map that the VOS algorithm builds, items are close to one another if they share more references, which means they belong to the same 
theoretical perspective or approach [17]. Also, clusterization is performed, with additional mathematical steps grouping items with a larger number of shared references. Papers belonging to the same cluster are strongly linked as a group, indicating a possible area of research [17].

In order to effectively analyze the high volume of obtained data, we limited the similarity analysis to papers sharing a minimum level of relatedness to the rest of the dataset. We subsequently used a calculated link strength measurement interval ( $\max 3,803$; min 50), which ensured the inclusion of all the relevant papers focusing on NPD research. The result was a dataset of 1,226 interconnected papers (93\% of the initial dataset) whose bibliometric activity indicators are presented in the next section. The graphical output of the VOS similarity analysis shows five well-defined clusters linked by a strong matrix of interconnections (see Figure 1 in the next section).

The fourth step comprised the literature review based on VOS aggregation results [24]. We analyzed each cluster's content to highlight the main papers within each stream and the primary connections between the clusters. Due to the high number of papers included in the main dataset, we selected a sample of the most relevant papers to review. Based on similar studies on a massive number of papers [1], [21] and the best methodological practices [20], we manually selected papers to review within each cluster by using the following criteria, in order of priority: (1) normalized citations $\geq 0.50$, (2) total citations, (3) authors' manual and independent refinement of the dataset. The latter criterion was necessary in order to avoid losing little cited but relevant papers. The manual selection led us to a restricted dataset of 899 papers. On this restricted dataset, three of the four authors performed three multiple human subjects independent reading process. The first one was aimed to generate a series of topics within each cluster. Following the prescriptions proposed by the existing relevant methodological literature [20], [21], [24]-[26], each of the three authors performed an autonomous and independent open coding of all the 899 papers by creating a series of topics that could summarize the main areas of research within each cluster. The authors then performed a series of meetings to exchange ideas and debate on the topics previously identified by each of them independently. The results of these meetings are represented by the lists of topics in Table 3 . The second multiple human subjects independent reading process was aimed to assign each paper to a specific topic, while through the third one, we scored all these 899 papers in the function of their significance for the topics to which it had been assigned and its relevance for the NPD field of study. We made a series of meetings between authors in order to reach an agreement regarding which topic a paper should be assigned as well as regarding the score assigned to each paper. The process led us to select 74 representative papers.

In the fifth and final step, in order to assess the reliability of our topic creation and paper selection processes we performed in the previous step, - paper allocation to the topics, selection of a reduced amount of relevant papers to be reviewed in the present study- we asked a panel of five experts in NPD (external to the authorship of this paper) to examine and review our paper selection process and results [20], [24]. This review process led us to conclusively identify 78 papers, representative of the business and management NPD studies over the last ten years (2008 to 2018). 
Please note that from this point forward, we use the following keys: (1) NP, reflecting the sum of the number of papers published in a journal, by an author, or within a cluster; (2) TC, reflecting the total number of citations collected by a paper, an author, a journal, or within a cluster; and (3) TCN, reflecting the normalized citations of a paper, an author, a journal, or within a cluster. The TCN is calculated by weighting the TC by the number of citations distributed within the dataset's time frame. While the TC tends to highlight older papers, the TCN is balanced to equally highlight newer papers that have had less time to collect citations. The size of the bubbles in Figure 1 and Figure 3 reflects the TCN value. (4) AGR-NP, showing the average growth rate of the number of papers inside a cluster. It is measured by averaging the percentage growth within each couple of years included in the 2008-2018 period. (5) TC/NP, which represents the average number of citations per paper and is calculated by dividing the TC by the NP.

\section{Results of the Bibliometric Activity Indicators and the VOS Analysis}

Table 1 shows the leading journals on which NPD studies in the field of business and management have been published in the 2008 to 2018 period.

\begin{tabular}{|l|r|r|r|}
\hline Journal & NP & \multicolumn{1}{|c|}{ TC } & TCN \\
\hline Journal of Product Innovation Management & 234 & 6158 & 289.89 \\
\hline Industrial Marketing Management & 60 & 1302 & 88.40 \\
\hline IEEE Transactions on Engineering Management & 46 & 537 & 31.58 \\
\hline R\&D Management & 37 & 617 & 33.32 \\
\hline Journal of Business Research & 35 & 394 & 44.31 \\
\hline Research-Technology Management & 34 & 353 & 26.99 \\
\hline Journal of Engineering and Technology Management & 32 & 453 & 31.31 \\
\hline International Journal of Innovation Management & 31 & 13 & 4.18 \\
\hline Technovation & 30 & 1018 & 45.26 \\
\hline International Journal of Operations \& Production Management & 30 & 370 & 34.50 \\
\hline International Journal of Technology Management & 30 & 229 & 8.02 \\
\hline Journal of Business \& Industrial Marketing & 29 & 250 & 16.58 \\
\hline African Journal of Business Management & 20 & 39 & 1.23 \\
\hline Management Science & 18 & 524 & 23.81 \\
\hline International Journal of Project Management & 17 & 278 & 18.36 \\
\hline Creativity and Innovation Management & 17 & 171 & 16.01 \\
\hline Journal of Marketing & 16 & 1039 & 41.79 \\
\hline European Journal of Operational Research & 15 & 198 & 15.86 \\
\hline
\end{tabular}

Table 1 - Main journals on the topic of NPD with at least 15 papers published

Journal of Product Innovation Management has the highest number of papers and citations. IEEE Transactions on Engineering Management is in the podium of the leading journals ranking as the third journal in terms of the number of papers (NP), thus confirming its prominent role also in the field of business and management [15]. Technovation, despite having only 30 published papers, collects 1,018 TC, to demonstrate its strong relevance in the NPD field. 
Figure 1 shows the graphical output of the VOS analysis. It highlights the presence of five wellpolarized clusters characterized by the following themes (1) Red cluster: the NPD process; (2) Green cluster: Diverse knowledge sources' integration for the NPD success; (3) Blue cluster: NPD and corporate strategy; (4) Yellow cluster: The role of users and consumers in the NPD process; (5) Purple cluster: Supplier involvement in the NPD process.

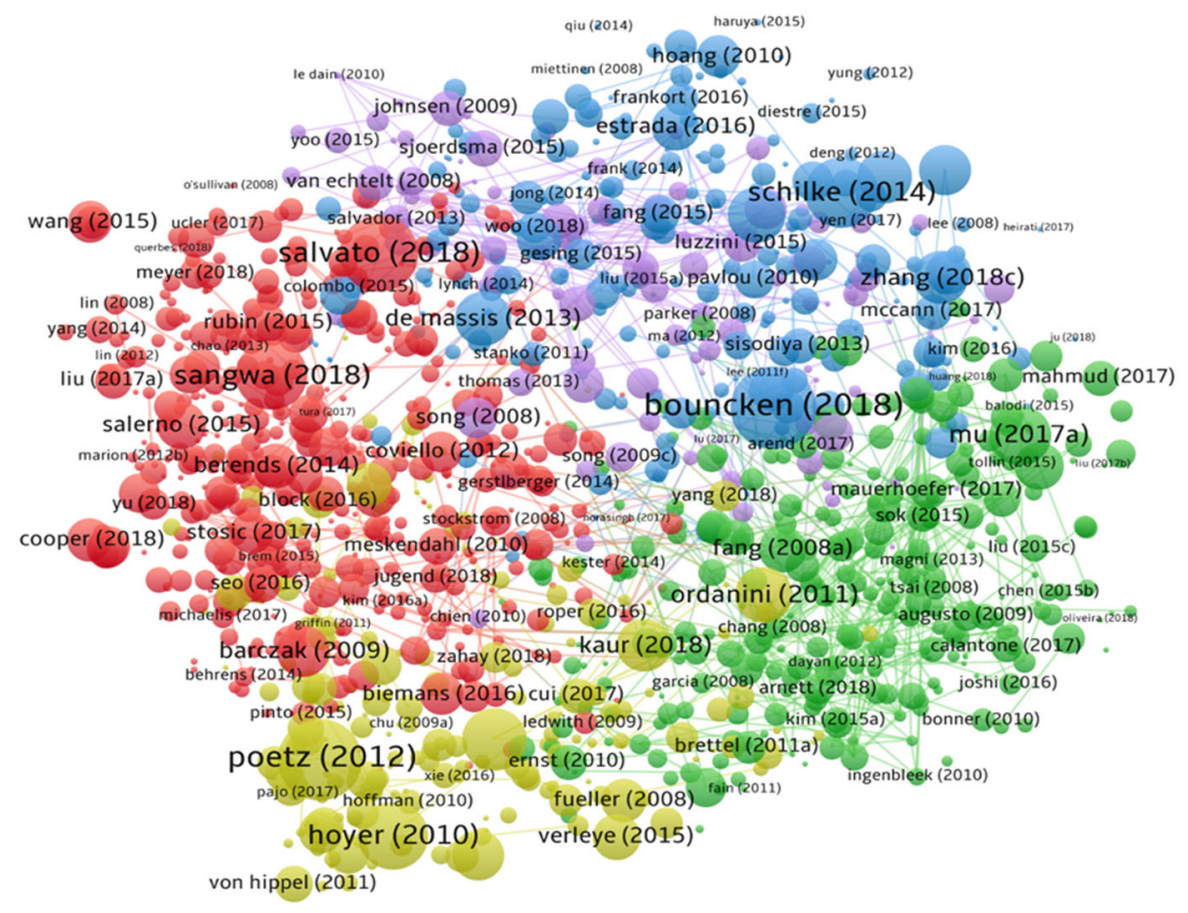

Figure 1 - Graphical output of the VOS analysis

In the red cluster, which represents the core of the NPD field of study, we find the largest number of traditional studies on how to develop new products effectively and manage the NPD process. The green cluster is the most heterogeneous one in terms of sub-topics, such as NPD team management, market orientation, and speed to market, which are, however, tied together by the knowledge-based view theory [27]. Based on the assumption that NPD is crucial for companies' strategy, the blue cluster encompasses strategic issues related to NPD, such as alliances and co-opetition, company openness, and R\&D strategy. Following the growing importance of users' involvement in the NPD process, the yellow cluster mostly comprises papers published in marketing journals and concerned with user co-creation, lead users, and users' ideas. Finally, the purple cluster explores how to strategically involve suppliers in the NPD process, thereby being strictly linked to the blue cluster. In Table 2 and Figure 2, we provide a descriptive analysis of each cluster and its development over time. The red cluster is the biggest in terms of the number of papers, being almost double the size of the green cluster, which is the second biggest. The growth rate in terms of published papers in the 2008-2018 period (GR-NP) was $+9.0 \%$, over the dataset's average growth rate of $+13.4 \%$. Similarly, the average number of citations per paper (TC/NP) is 15.8 , while that of the dataset is 18.6. In contrast, this cluster's TCN is much higher (415.4) than the average TCN of 248.3. These findings suggest that the red cluster, which represents the core traditional NPD literature, is reaching a maturity period, as 
previous NPD literature reviews predicted years ago [1], [3]. Likewise, as shown in Figure 2, the size of the red cluster remains stable over time, providing NPD research with continuous theoretical support. The green cluster, the second largest in terms of the number of papers and TC, has a relatively low AGR-NP (+6.1\%). However, its TC of 5,101 and TC/NP of 21.4 are particularly high, showing that, though growing at a relatively slow rate, research on diverse knowledge sources for NPD is receiving more citations. The blue cluster is among the fastest-growing $(+15.4 \%)$ in terms of NPs. Figure 2 shows its constant NP growth, which reflects scholars' increasing attention to NPD's role in corporate business strategy. Like the blue cluster, the yellow one represents a recent and fast-growing area of research (AGR-NP $+13.3 \%$ ), which has seen continuous NP growth from 8 in 2008 to 19 in 2018. Its TC/NP is high (22.5), showing that it has a high impact in terms of TCs per paper. Finally, the purple cluster is the smallest but the most stable in terms of NPs over the years. AGR-NP is the highest (+22.9). Data suggests that, while supplier involvement in the NPD process is a relevant topic (as confirmed by a high TC/NP of 20.11), the space for academic research advancement within this cluster seems currently relatively limited.

\begin{tabular}{|c|c|c|c|c|c|c|}
\hline & $\begin{array}{c}\text { Red } \\
\text { cluster }\end{array}$ & $\begin{array}{c}\text { Green } \\
\text { cluster }\end{array}$ & $\begin{array}{c}\text { Blue } \\
\text { cluster }\end{array}$ & $\begin{array}{c}\text { Yellow } \\
\text { cluster }\end{array}$ & $\begin{array}{c}\text { Purple } \\
\text { cluster }\end{array}$ & Totals \\
\hline Number of Papers (NP) & 449 & 283 & 207 & 179 & 108 & 1,226 \\
\hline Total Citations (TC) & 6,966 & 5,101 & 3,174 & 4,028 & 2,172 & 21,621 \\
\hline $\begin{array}{c}\text { Normalized Total Citations (TCN) } \\
\text { Number of Papers' Average Growth Rate } \\
\text { (AGR-NP) }\end{array}$ & 415.4 & 264.1 & 233.9 & 224.2 & 113.5 & $1,251.1$ \\
\hline Total Citations/Number of Papers (TC/NP) & 15.0 & $+6.1 \%$ & $+15.4 \%$ & $+13.3 \%$ & $+22.9 \%$ & - \\
\hline
\end{tabular}

Table 2 - Bibliometric activity indicators of each cluster
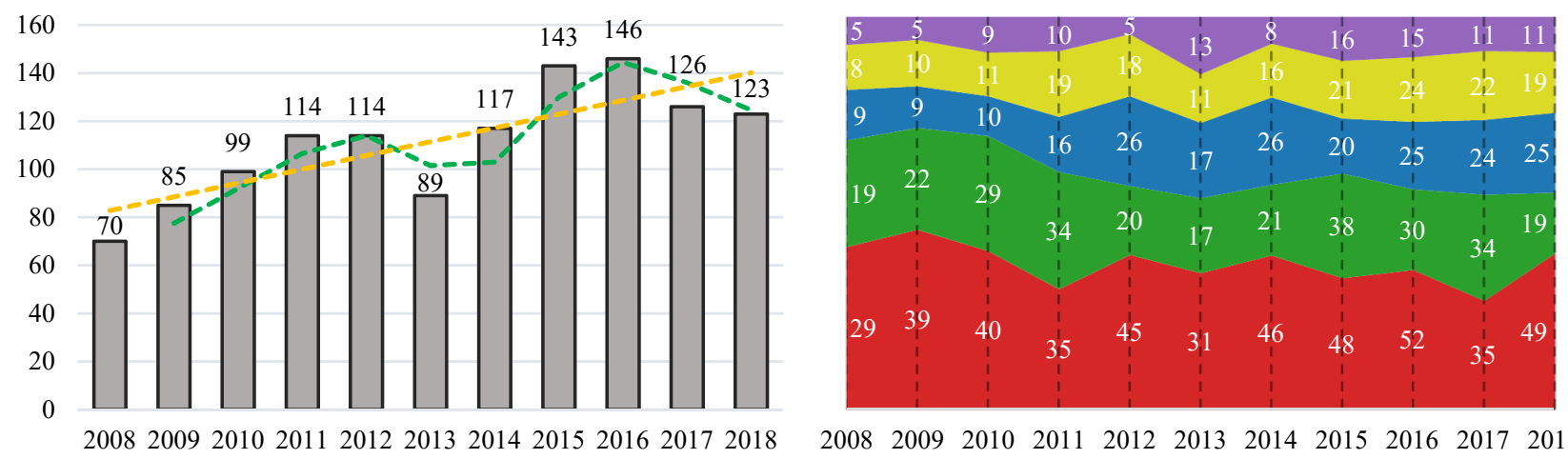

Figure 2 - Distribution of the papers by years (left) and years-clusters (right)

\section{Results of the Literature Review}

In the following section, we present the results of the literature review as emerged from the VOS analysis. Figure 3 highlights the themes that emerged from the literature review process. 


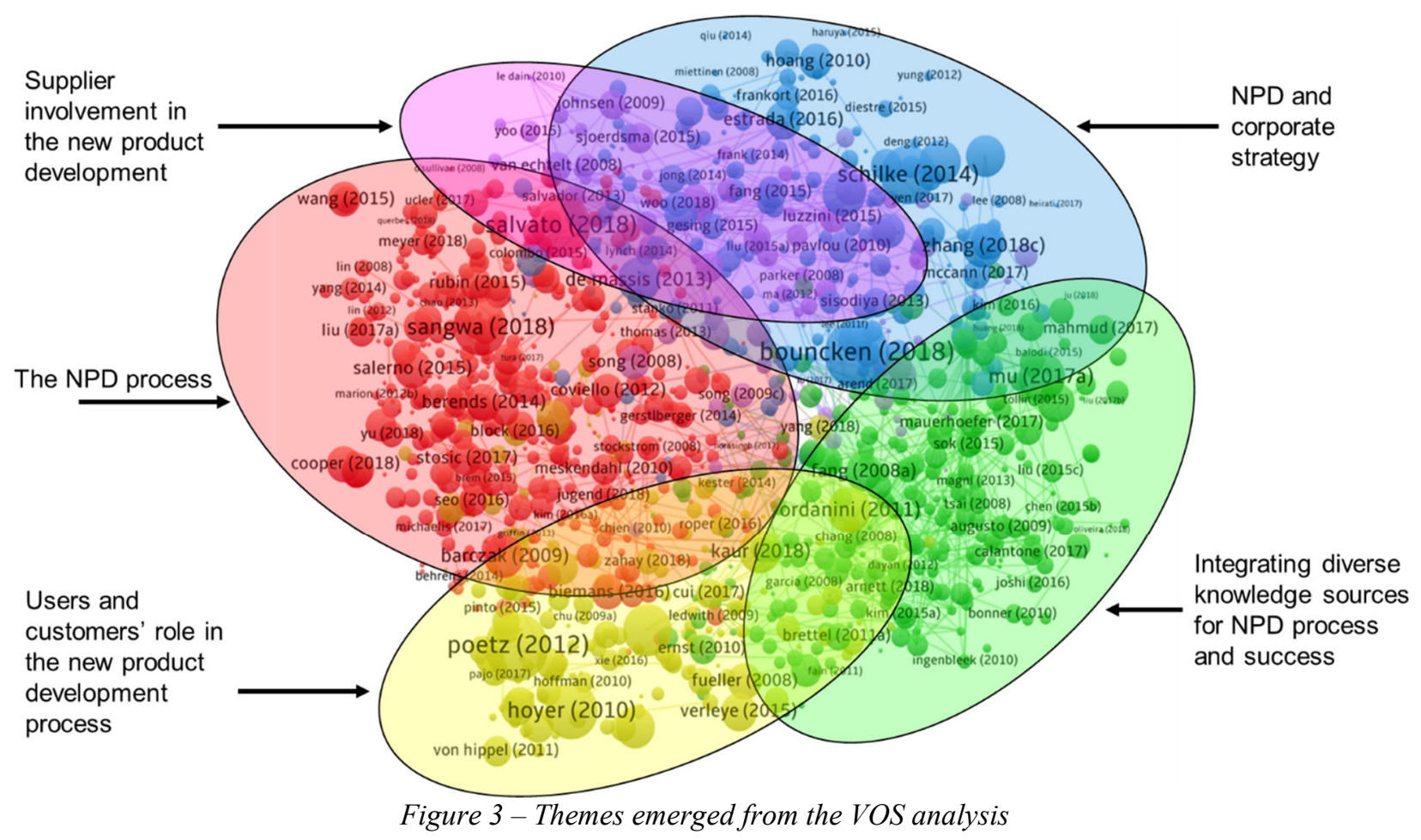

\subsection{Red cluster: The NPD process}

The red cluster represents the core of the NPD field of study. We start our literature review with PDMA-sponsored best practice research projects [4], [5], which is designed to help managers improve their NPD practices. The results from these studies highlight that, compared to the last decade, companies had become more cautious regarding NPD portfolio projects (resulting in a lower percentage of new-to-the-world projects) experiencing a decline in sales and profits due to their conservative approach. The 2012 update of the PDMA study [7] identifies an urgent need for NPD best practices' to be diffused among practitioners together with the demand to translate into practice the tools developed by researchers. The study highlights that successful NPD processes are strongly connected with the company's strategy. Therefore, the NPD strategy and process should go hand-byhand with a company's strategic development.

In this vein, researchers call for new, flexible, and iterative approaches to NPD compared to traditional linear and sequential NPD models such as the Stage-Gate approach [28]. For example, based on a survey of 120 projects using the Stage-Gate process for NPD, Sethi and Iqbal [29] demonstrate that the strict application of linear and rigid NPD models reduces organizational learning and affects new products' performance negatively.

Following the abundant shreds of evidence regarding the drawbacks associated with linear approaches to the NPD process, several authors propose less structured approaches by adopting an Agile-Stage Gate hybrid philosophy [30], [31] or by integrating open innovation into the NPD practice [32]. Salerno et al. [33] highlight that the NPD process should follow a non-linear pace by adapting itself to the market and/or technology needs. After a new product's preliminary launch, the 
company should wait for the existing market to develop, reducing the uncertainty before launching a new version of the product.

In line with the new trend and necessity to develop flexible NPD models, several authors propose operative tools aimed to increase the flexibility of the traditional NPD approaches [30], [31], [34], [35]. The creators of the Stage-Gate model [34] propose an examination and an update its original principles in order to increase the NPD process's productivity based on (1) a customer-focused approach, (2) an extensive NPD assessment (financial, market, and technical) in the early stages of the development process, (3) a spiral development, (4) a holistic approach driven by effective crossfunctional teams who share knowledge effectively, (5) metrics, accountability, and continuous improvement to keep track of the NPD process's performance, (6) a focus and active portfolio management to integrate all the developed products into the company strategy, (7) and the implementation of the NexGen Stage-Gate Process (Agile-Stage-Gate Hybrid Model) which represents the evolution of the NPD process toward a more flexible approach by including Agile principles. The effective application of the Agile-Stage-Gate Hybrid Model has been demonstrated by an extensive study on the toy company LEGO [30] where these new principles are applied and resulted in a more efficient response to customer needs and preferences, better team communication, and improved NPD productivity. The lean manufacturing approach also demonstrated its ability to reduce the time of the development cycles by transforming the linear NPD processes into flexible and iterative ones [36]. In particular, recent research proposes an integrated lean manufacturing performance measurement framework that managers can apply to measure lean implementation's effect [37]. It focuses on 26 sub-dimensions and 119 key performance indicators able to capture lean manufacturing's impact on finance, supplier management, human resource management, administration, manufacturing process, new product development, and customer management.

Few scholars explore the organizational factors affecting the NPD process, even though there is a consensus that it involves the organizational dynamics intensely [6], [7], [38]. For example, the role of organizational memory could play a crucial, albeit ambiguous, role in the NPD success [39]; memory and knowledge sharing between organization members through open communication and cross-functional teams could help accomplish tasks on time and more effectively, especially when a project is highly innovative [39]. Similar to organizational memory, an effective balance between the conflicting organizational goals of NPD design quality and NPD efficiency is facilitated by specific organizational routines such as (1) splicing, i.e. the recombination of activities and participants, resulting in a broader debate on the NPD project and aiming to include different perspectives on and opinions about the project; (2) activating, i-e. encouraging people involved in an NPD project to work together in order to find a balance between their conflicting points of view; (3) repressing, i.e. switching the NPD process's activities and participants off when they are no longer necessary to minimize different points of views that could create barriers to a fluid NPD process [40].

There is also a substantial body of knowledge related to NPD in small and medium enterprises (SMEs) showing that the characteristics and requirements of the NPD process in SMEs are quite different compared to those of large companies. For example, the frequent presence of highly centralized 
family governance structures strongly impacts the NPD design decision making [41], as well as the entire NPD process. In family-owned SMEs, cross-functional teams are associated with a lower NPD performance, because they face severe conflicts between the established routines and innovation activities. Furthermore, unlike larger companies, in family-owned SMEs it is usual that the same person handles different roles, such as project leader and product champion [41]. The NPD practices of SMEs differ from those of large companies also regarding market orientation as for these firms competitors orientation represents a crucial market orientation element in generating a superior new product performance [42]. These findings suggest that SMEs should be aware of a new product's impact on their market positioning, on what their competitors offer, on their financial performance, and should avoid the trap of over-focusing on just a small market segment [42].

Thus, the role of customers' involvement seems crucial for the success of SMEs' NPD processes [43]. Coviello and Joseph [43] compare three successful innovation projects with three unsuccessful ones and find that successful projects are those where the customers are actively involved in the following six NPD activities: opportunity recognition, customer-based funding, development, testing, commercialization, and feedback. These activities provide SMEs with continuous input from their customers during the NPD process, using an approach similar to the Agile method for software development. Given the difficulties of explaining SMEs' NPD process using traditional innovation theories, Berends et al. [44] propose an interpretative framework based on effectuation theory that distinguishes between two approaches to decision making: causation, which assumes that means are selected in order to reach the goals, and effectuation, which assumes that the available means shape the goals. The study shows that SMEs approach the NPD process differently compared to larger firms. SMEs use their existing resources creatively, limit their innovation process to those advancements considered possible with available resources, use external knowledge sources extensively, prioritize their existing businesses instead of creating new ones, and rely strongly on customer feedbacks and knowledge. This set of findings opens an interesting debate on shaping NPD practices based on the company size category in which they have to be applied.

A relevant topic identified within the red cluster concerns new service development (NSD). NSD has grown considerably over the last ten years due to the increasing servitization of businesses and changes in manufacturing industries [45]. Kindstrom and Kowalkowski [46] propose a four-stages circular service development framework for manufacturing companies. The framework starts with sensing the external environment in order to create long-term relations with the relevant actors to cocreate new services. Next, during the development, the identified actors are actively involved in the process, to a more considerable extent compared to NPD projects. The third stage, sales, should focus on understanding how the service could increase the entire customer experience (e.g., through effective maintenance services and after-sale support). Finally, during the last stage, i.e. delivering, the companies need to account for long-term relations with the costumers due to the very nature of services that are co-created by interacting with users throughout the delivery process itself. In this regard, NSD should encompass modularity principles coming from products [47]. Complex products often require services like maintenance and training; consequently, NPD often goes hand in hand with 
NSD. The importance of integrating new products and complimentary services is pivotal to increase customers' satisfaction [48]. The value-in-use of a product and its relative attached service is related to the presence of an effective relational dynamic and access [48]. The first is the capacity to create a positive relationship with customers by offering each client a tailored experience (e.g., a dedicated repair and support service for professional/business users). The second refers to offering a support service available to clients outside regular business hours. It is essential for professional and business users, who, for example, may need a repair over the weekend in order to have their appliance working during the week. Therefore, companies should pay keen attention to developing support services that could increase the final products' quality, primarily for advanced-user categories.

Finally, Biemans et al. [49], by analyzing 230 empirical papers, showed that applying NPD approaches to the NSD domain has biased most published research. In other words, few scholars paid adequate specific attention to NSD, with the result that the NSD research field still lacks a comprehensive and holistic theoretical framework.

\subsection{Green cluster: Integrating diverse knowledge sources for NPD process and success}

The two most recent studies on NPD best practices, which we reviewed at the beginning of subsection 3.1 [6], [7], highlight that among the various aspects that need urgent improvements there are cross-functional integration, team communication support, and the integration of a diverse set of knowledge sources. The studies included in the green cluster adopt the knowledge-based view of the firm, which considers knowledge as a critical resource that organizations need to manage, integrate, and use to enhance their corporate performance [50].

The first issue emerging in business processes involving a high level of knowledge, such as the NPD process, is the storage and diffusion of the knowledge that is necessary to implement these processes effectively. Recent studies confirm that a first step to effectively managing knowledge within complex processes is to seek the help of IT tools [51]. Market data management tools allow companies to understand market needs, generate ideas, and select these ideas in a data-driven process supported by analytical software. Studies show that the effectiveness of IT tool usage is positively associated with NPD performance because it facilitates the retrieval and the use of knowledge among the company's functions involved in the NPD process [52].

Based on the knowledge-based view, a large amount of literature inside the green cluster focuses on cross-functional integration (CFI) among R\&D, marketing, sales, and other functional areas.

While it is clear that a high level of collaboration between sales and R\&D is crucial in the concept development stage, and has significant positive effects on NPD performance [53], other moderators affect CFI impact on NPD performance [54]. A successful CFI depends on a complex combination of factors such as the climate of cooperation as well as information sharing, no more than two functions being involved, using product effectiveness instead of market indicators to measure NPD performance [54]. CFI's effect on NPD process performance is also discontinuously distributed across the entire NPD process [55]. For example, integrating the R\&D and marketing functions impacts NPD process efficiency positively, but not effectiveness because, in the latter case, the impact also 
depends on the NPD stage. On the other hand, the integration of R\&D and manufacturing has a positive impact on efficiency during the development stage [55]. Finally, pursuing explorative (instead of exploitative) innovation and an aggressive innovation approach positively affect the relationship between CFI and NPD performance, while environmental uncertainty does not affect it [56].

Recent studies focus on how to manage CFI at the micro-level of the team. Nakata and Im [57] explore the difficulties of integrating team members with divergent orientations and expertise. Team characteristics, such as social cohesion, process formalization, and managerial encouragement to take risks, can influence teams' CFI. Specific team behaviors (caring), beliefs (psychological safety), taskrelated processes (shared problem solving), and governance mechanisms (clear management direction) can create a climate that fosters CFI and team effectiveness [58]. Shared problem-solving and caring behavior can support learning and the time efficiency of interfunctional teams. Team psychological safety is positively related to learning; clear management direction is positively associated with CFI efficiency; shared problem-solving is positively related to NPD outcome [58]. These findings clearly show that team management's best practices are among the most significant factors of NPD process success.

Finally, a sub-area of research relates to the role that a company's market capabilities and orientation play with regard to NPD success. Ramaswami et al. [59] show that if a company is strongly connected to the market, its functions can respond to market feedbacks quickly, resulting in a better NPD's financial performance. Also, market orientation, CFI, and NDP performances are strongly connected [60]. When companies are market- and competitor-oriented, they are more likely to spot trends and customer needs; resulting in better implementation of new-to-the-world products. However, the company's innovativeness, competitive strength, and market orientation are less effective if CFI is not adequately developed and managed across the organization [60].

\subsection{Blue cluster: NPD and corporate strategy}

The dynamic capabilities theory recently focused on the NPD process and its pivotal for the company's superior performance and survival [10], [11]. By reconfiguring the NPD process according to the market and technology needs, the company can effectively adapt to turbulent environments and deal with uncertainty and rapid technological changes [11]. The capacity to continuously reconfigure the NPD process is not only connected with the company's survival in a dynamic environment but is also linked with a superior NPD performance [10]. The development of specific capabilities such as sensing the environment and learning, coordinating, and integrating resources allow a company to adapt and better respond to an uncertain environment, thereby allowing to obtain increased NPD efficiency and new products' effectiveness [10]. However, empirical evidence demonstrates that when the environment is highly turbulent or extremely static, the dynamic capabilities' beneficial role is weak as dynamic capabilities are inverse U-shaped connected to competitive advantage and environmental dynamism. [61]. In this line, the NPD alliances represent an alternative way for companies to acquire the knowledge, resources, and capabilities needed for effectively developing 
new products. However, managing one or more NPD's strategic alliances presents a series of critical issues, especially related to the counterpart opportunism [62]. Several barriers, such as the environment's legal and regulatory characteristics, can influence the integration of complementary knowledge in strategic alliances [8]. When the partners' interdependence is high, the knowledge complementarity allows the development teams to interact significantly, resulting in a higher NPD process innovativeness [8]. However, when the knowledge expropriation risk is high due to weak legal and regulatory environments, the interdependence between the partners impacts the NPD process innovativeness negatively due to possible opportunistic behaviors [8]. Having a high level of technological capabilities helps companies to gain significant advantages from alliances and reduces the risks connected to partners' opportunism, especially when dealing with partners from emerging economies where knowledge integration is difficult due to the lack of trust and intellectual legal protection that characterizes the legal systems of these economies [62]. Another aspect to be considered in the context of NPD's strategic alliances refers to the timing in product co-development with upstream and downstream partners [9]. The first generally face a higher risk of opportunism, which is associated with product specificity and the high amount of resources invested in a technology tailored to the downstream partner's need. The latter has significant bargaining power and consequently tends to adopt opportunistic behaviors by overturning most of the risks to the upstream partners [9]. Considering that cooperation has different effects, depending on the NPD process's stage [63], knowing when and with whom to cooperate is crucial for a successful NPD alliance.

The company's innovation capabilities are primarily improved if cooperation occurs during the concept and product development stage, but it more positively affects NPD success if it occurs during the implementation stage [63]. On the other hand, vertical, horizontal, and institutional cooperation with other companies fosters a business's success, while cooperation with institutional partners has an additional positive effect on the entire NPD process's performance [63]. Also, the type of innovation, radical or incremental, strongly influence collaborations' effectiveness [64]. When innovation is incremental, cooperation with competitors leads to better results concerning design, functionality, product features, and quality in all the development phases, but it has a stronger positive effect on the pre-launch phase. Conversely, when innovation is radical, co-opetition benefit emerges in the product launch phase only. Therefore, when innovation is incremental, it is better to cooperate with competitors through the entire NPD process, while when it is radical is a good practice to protect the own knowledge until the product's launch. [64]. Finally, an effective internal R\&D capability is needed to master R\&D alliances since a low external exploration experience could facilitate opportunistic behaviors from the other counterpart [65].

Scholars have also explored open innovation's effects on the NPD process in respect of the interactions and the information flows that fosters the innovation performance. Findings suggest that companies need time to develop the capabilities required to successfully incorporate the open innovation approach into the NPD process [66], while an excessive openness may have adverse effects on the NPD process [67]. Although companies have a better short-term NPD performance if they adopt open collaboration strategies, when the level of openness significantly increases the 
medium-term NPD performance tends to get worse as projects tend to become slower and more expensive compared with the industry average [67]. Also, the extensive use of an open approach does not often provide a superior innovation outcome in terms of product quality and performance and often results in higher costs compared with non-open projects [68]. Therefore, a significant degree of openness brings to negative NPD performance, as does a low degree of openness [68]. Finally, also contingency projects' characteristics affect performance in open innovation-driven NPD projects. When NPD projects are explorative, an open approach is better in the ideation stage; if the NPD project leader has prior open innovation and management experience and an organizational climate that supports creative endeavors is present, the open approach seems to perform better [68]. Open innovation may be a useful source of knowledge under certain conditions, but pursuing an extreme open strategy might not always be the best choice.

\subsection{Yellow cluster: Users and customers' role in the new product development process}

After the introduction in 1968 by Eric von Hippel [69] of the concept of lead user as a source of product innovation, the entire body of knowledge regarding the role of users in the NPD process moved towards a "democratizing innovation" direction [70]. In 2011, von Hippel et al. [71] reinvigorate the attention of the scholars on this point by identifying a new three-phases paradigm that sheds fresh light on the mechanisms through which users' innovation emerges. Initially, users themselves develop products that satisfy their needs. Next, when the product is on the market, other users evaluate, reject, copy or improve products developed in the first phase. Finally, once a product's potential has become clear and the uncertainty has decreased, mass producers enter the market [71]. As they adopt new products more readily and faster than ordinary users, lead users play a crucial role in the creation and diffusion of new product concepts, thus becoming a highly valuable resource for marketers [72]. Also, co-creation communities provide feedbacks on lead users' ideas and help them diffuse their innovations outside communities' boundaries, facilitating the development of prototypes and the products' diffusion to the early majority [73]. Recent studies also propose a reflection about the NPD performance implication of users' generation of ideas [13], [74]. By comparing the characteristics of ideas generated by two groups, "crowds" of users and professionals, it has been shown that, even if the feasibility degree of novel ideas from the crowd is lower, the overall benefit generated by involving both groups of users seems higher than the costs [74]. The meta-analysis by Chang and Taylor [13] highlights that users should be involved in two critical stages of the NPD process: idea generation and the launch stage. Users' involvement has a positive impact on the speed to market and a moderate impact on the NPD financial performance. Also, market turbulence influences the need for user's involvement: the higher the market turmoil, the more user contributions are needed. The meta-analysis also shows that the NPD performance obtained through users' involvement is far more effective in low-tech industries as in less complex industrial contexts it is easier to integrate users' knowledge into NPD activities. Finally, users' involvement results in a superior NPD performance in SMEs rather than in large companies, which also applies to firms from emerging countries, where users' needs have been less explored [13]. The involvement of users in the 
co-creation process also positively impacts the market image of the company. Involving users tends to spread a positive word of mouth about the company even within the mass not involved in the cocreation process [75], thus generating positive effects on the demand for co-created products compared to the same products which have not been co-created [76].

Though the abovementioned studies clearly outline the positive effect of involving users in the NPD process, they do not clarify where and how a company should look for engageable users and how to obtain insights from them. In this vein, brand community members are valuable users to involve in the co-creation process since their brand community identification and brand knowledge are significant factors affecting consumers' inclination to share their knowledge with producers [14]. For example, the LEGO company succeeded in creating a sustainable producer-user ecosystem in order to ensure users' continuous and active involvement [77]. Several companies, such as Coca-Cola, Toyota, and Mazda approached the users' involvement through the use of automated online tools and virtual worlds [78]. The use of virtual worlds to simulate users' behaviors and gain insight from them is a recent development of co-creation techniques [78]. With a relatively low investment, companies can gather insights from users that are geographically distant, thus allowing both managers and final users to interact effectively and share their insights for a sound NPD management [78]. Contrary to virtual worlds, which can only involve a relatively limited number of users, automated methods based on machine learning allow insights to be gathered from a much larger number of users [79]. Machine learning approaches are particularly useful in assisting managers and NPD developers in screening ideas that users produce in real-time, which can then be evaluated in the development process's subsequent stages, resulting in a $48.1 \%$ increase in the NPD process performance [79]. Machine learning approaches can effectively process online customers' reviews by combining automated analysis tools with conjoint analysis in order to collect insights about which product's attributes are must-have and which are optional [80]. Finally, the screening process can now be effectively supported by artificial intelligence during, that nowadays reaches a screening performance comparable to that of humans, but requiring less time and resources [81].

Co-creation processes and user involvement are also crucial in the case of NSD, where the role of experience and experimentation is even more critical because customers create the service when they use it [82]. The use of classic techniques, such as brainstorming, does not seem adequate for new service co-creation processes because, unlike the NPD case, the limited experience of involved users represents a significant barrier to their involvement [74]. Ordanini and Parasuraman [83] explore the type of innovation users could contribute to in the NSD process and find a substantial divergence between the user contribution to the co-creation of new services and physical products. In the NPD co-creation process, users often produce ground-breaking ideas, while in the NSD co-creation process, users' contribution is focused on incremental innovation and is unlikely to produce radical innovation [83].

Identifying the right users to be involved in the NPD co-creation process represents an emerging topic. In this regard, Hoffman et al. [84] propose an inventory test aimed at measuring certain personality traits of the users involved in the co-creation process. Their results show that consumers 
can be characterized by an "emergent nature" which is defined as the unique capability to imagine how new product concepts should be developed. These consumers can improve a product concept effectively, but also help make it useful, appealing, and thriving to the market. While lead users tend to be visionary and to propose products with futuristic features emphasizing the product's hedonic value, users with a pronounced "emergent nature" prefer to accentuate the product's utilitarian attributes, which are more useful for the average final user [84].

\subsection{Purple cluster: Supplier involvement in new product development}

The NPD process involves different categories of actors. The core aspect of the purple cluster is the supplier involvement in developing new products. Companies increasingly outsource stages of the NPD process to suppliers in order to benefit from their expertise, reduce the NPD processes' costs and improve the time to market [85]. The interest in integrating suppliers' knowledge and expertise in the NPD process starts from the '80s in the automotive industry where it proved to be one of the main sources of competitive advantage for Japanese companies [2]. Later on, several other studies have focused on how to integrate the supplier into the NPD process effectively and confirmed that suppliers' involvement is a crucial variable for superior performance even for U.S. and European firms. The evolution of this field raised several questions regarding the role of trust and commitment, especially in B2B relations with suppliers [2], [85].

However, despite how research on supplier integration into the NPD process has largely evolved, a holistic framework embracing all the aspects concerning the knowledge exchange and relationship management connected to supplier involvement is still lacking. To address this need, Sjoerdsma and Weele [86] propose a framework highlighting 12 constructs that positively affect supplier involvement in the NPD process. The quality of the relationship between the supplier and the customer is a crucial predictor of NPD performance in terms of product quality, cost, and time to market. Organizational and individual variables also affect this relationship. Satisfaction, adaptability to relationships, loyalty, reputation, attractiveness as a customer or supplier, and competency influence the quality of the relationship positively from the organizational side. Trust, quality of the communication, knowledge sharing, cooperation, commitment, transparency, and flexibility are fundamental for suppliers' and buyers' successful integration into the NPD process from the individual side. [86]. Furthermore, a high level of collaborative competences is required from both sides, especially for the activation of effective knowledge sharing mechanisms [87]. If a supplier does not meet the buyer's quality expectations, the company should intervene to evolve the supplier's capability by activating a bilateral knowledge-sharing process aimed to improve the supplier's creative and technological capabilities [88].

Finally, Cousins et al. 's [89] findings confirm that knowledge sharing mechanisms and the technical proficiency offered by suppliers are vital for developing breakthrough product innovation. In this regard, Song and Di Benedetto [90] explore the antecedent and the performance implication of supplier engagement in radical innovation. Their results show that suppliers' specific investments in 
technology and a company's effort to improve their suppliers' abilities are critical drivers of supplier involvement that ultimately results in better NPD performances and radical innovation outcomes.

\section{An Agenda for Future Research on NPD}

Intending to propose a guide for scholars interested in exploring the main research gaps that emerged from our literature review, in the present section we present a research agenda for NPD future research composed of a series of wide-spanning research questions. We hope that these questions can help researchers and practitioners to reflect on the emerging research themes described below and effectively unpack them in specific pieces of research.

\subsection{Red cluster: The NPD process}

While traditional linear NPD models are still the dominant approach for the NPD process [4], [5], [7], attention to more flexible or "hybrid" approaches is increasing [28], [91]. Although recent literature broadly supports the need for these approaches, their identification, design, and implementation need to be further investigated [92]. The first questions that scholars and practitioners should investigate refer to how companies that are using linear NPD models could easily and quickly evolve their process to the new flexible or hybrid approaches. Especially for Agile-based flexible approaches, which are mainly coming from the software industry, there is a need to clearly understand "what" principles can be applied to the manufacturing companies, and more broadly, to NPD and NSD outside the software industry [92], [93]. Also, there is a strong demand to identify and develop an efficient system of key performance indicators capable of effectively monitoring NPD activities carried out using flexible approaches [94]. The available literature presents only a few pilot tools to measure Stage-Gate and Agile approaches' effects on the speed, costs, and quality of the NPD process [94]. However, there is no extensive tool that can capture the combination of Stage-Gate and Agile principles co-occurring in the same project, or sequentially across multiple projects [94]. Therefore, how can we easily measure and compare the performance of linear and flexible models? What are the performance indicators that should be included in a measurement tool? There is also a need for a tool that can measure, monitor, and manage contingent factors such as complexity, uncertainty, and other specific issues related to the different industrial contexts where these emerging principles models are applied. Regarding the nascent topic of start-ups and lean start-ups [95], how can Agile and Hybrid models be beneficial for those type of embryonic companies?

Furthermore, the research on NPD has mostly focused on the "hard" aspects of NPD success factors without fully explaining "which," "how," and "to what extent" non-technical "soft" aspects such as organizational culture, ambidexterity, or idea generation practices can influence the NPD process [96]. Few studies partially explored the role played by organizational issues [40] and family firms' climate [41]. Nevertheless, there is still broad scope for research on the "soft" aspects, like the organizational culture and the human factors [96]. Therefore, how does organizational culture impact the NPD process performance? Are there any organizational culture characteristics that could foster the outcomes of the NPD process? There is also a shortage of empirical research on NPD practices 
that could be implemented in contexts that differ from those of large for-profit companies, such as SMEs, benefit corporations, or non-profit organizations. With specific regard to SMEs, whose NPD process is usually strongly interweaved with entrepreneurship, using the effectuation-causation approach to the NPD process might be an up-and-coming research option [44]. More generally, there is a need for cross-national studies, further exploring the potential of using the effectuation-causation approach to the NPD process in organizations of different sizes and characteristics [44]. In connection with the organizational culture: is it possible to identify specific routines depending on where a product or a service is developed? Regarding the entrepreneurial culture: which is the different impact of using the causation-effectuation approach in large companies compared to SMEs? How does the causation-effectuation approach affect NPD teams in large companies compared to SMEs?

Finally, the NSD research field needs to be further explored [49], also by implementing an updated bibliometric and/or literature review. The service-dominant-logic theory (SDL) [83], which encompasses a company's collaborative competences, the dynamic capability of its customer orientation, and its knowledge interfaces [83], could be used as the theoretical lens. The SDL lens regards the NPD and NSD processes as nested together in an overarching service that integrates both tangible goods and connected services. SDL assumes that only services exist and that products are merely enablers of services. Therefore: what are the implications of the service-dominant-logic for NPD processes and best practices? Which are the best practices to develop a new "product-as-aservice"? [97].

\subsection{Green cluster: Diverse knowledge sources' integration for the NPD process and success}

Most of the research gaps in the green cluster relate a better understanding of the knowledge dynamics of CFI. Several papers outline a need to explore better the knowledge sharing and utilization dynamics behind the CFI process of information sharing [55], [56]. The analysis of the knowledge diffusion mechanisms should be better developed both at the business unit/department level, as well as within and between the teams involved [53], [54]. Therefore, what is the most effective CFI approach to store and diffuse the increasing level of knowledge available into departments? What are the implications of the increasing availability of data for the mechanisms aimed to share knowledge between departments? While the literature has already proposed some best-practices to foster CFI at the business unit/department level, there is a need to explore the CFI best practices further to be adopted at the team level. In other words, how can team collaboration be fostered between employees involved in a CFI initiative? What is the most suitable team composition for an effective CFI? In connection with the research avenues of the red cluster, the role of organizational climate seems crucial for the CFI-NPD performance relationship [58]. As a result: do we need to consider other moderators of the relation between CFI and NPD performance? What is the role of organizational culture in CFI at the team and the department level?

There is also a need to explore the effect of involving other functions, such as operations, manufacturing, design, and purchasing in CFI initiatives [53]. Most of the contributions related to CFI are focused on marketing, R\&D, and sales, while other forms of integrations still need to be 
explored. Therefore: how can additional company functions be involved in CFI? What could possibly be their contribution to a better NPD performance?

Furthermore, the need for additional comparative studies in different contexts has emerged. For example, the following questions need to be answered: What could be the effect of CFI in a businessto-business industry and in a business-to-consumer industry? Is CFI characterized by the same success factors and effects in different sectors? Are the CFI's success factors the same for NPD and NSD?

\subsection{Blue cluster: NPD and corporate strategy}

The research gaps which need to be bridged within the blue cluster are primarily focused on finding a new and effective pathway to leverage the NPD process within the company's strategy. A first exciting research avenue is related to the theoretical understanding of dynamic capabilities' role within the NPD process [10], [61]. Some of the questions that need answering are: what are the dynamics capabilities linked to and involved in the NPD process? How do the company capabilities interrelate with and influence the NPD process? Furthermore, given that our findings show that the NPD process plays a crucial role in a company's strategy, we could provocatively ask: can we consider the NPD capability itself as a dynamic capability?

Concerning the ongoing debate on alliances, collaborations, and co-opetition, while some best practices regarding when and with which partner to cooperate have already been proposed, there is still a need to explore more in detail this pivotal topic and provide more generalizable guidelines for managers [63]. Consequently, are the timing and selection processes of partners similar across different countries and industries? If not, what are the differences and best practices that should be adopted in different contexts? About selecting a private or public partner to cooperate with, can we propose a comprehensive set of best practices linked to the different stages of the NPD process? If not, under which conditions it is better to select a private or a public partner? There is also a need to better explore and exploit the role of users in strategic collaboration and how their contribution can be integrated into a company strategy [64]. Therefore, how could the capacity of a company to involve users be integrated into a strategic alliance aimed at co-developing new products?

Finally, the debate about the role that openness plays for NPD and company performance is in turmoil [67], [68]. In order to define best practices for managers, the relationship between openness and different levels of performance should be investigated, as well as contingency factors such as the industry and the country and the role of the institutions [98]. Straddling the red and the green clusters, contingencies concerning organizational culture, managerial style, level of market competition, type of CFI approach, and the technological turbulence should also be better explored, paying particular attention to their influence on the effects of company openness on NPD performance [68]. Several replication studies are therefore needed to understand better and exploit the short-term and long-term effects of openness on the NPD and overall company performance, also in the light of the above mentioned contingencies. Finally, there is a need to identify at which stage of the development 
process openness is positive for both the NPD and the NSD process beyond the idea generation stage [98].

\subsection{Yellow cluster: The role of users and customers in the new product development process}

The studies in the yellow cluster have not bridged the two following main research gaps yet: in which markets and conditions is co-creation a viable business strategy? How should a firm allocate its resources between internal NPD routines and co-creation activities in order to optimize the NPD performance [12]? These two gaps raise three future research avenues: (1) where can firms find valuable users to involve in the co-creation processes?; (2) which kind of users should be involved in order to achieve a better co-creation performance?; and (3) how can information be extracted effectively and efficiently from these users?

Regarding the first sub-area, a significant part of the abovementioned literature focuses on involving users from online communities. However, there is still a need to investigate how these communities should be managed in order to facilitate the multiple user-to-user and user-to-producer interactions, thus maximizing the effectiveness of the community-based co-creation process [77]. Moreover, while users are certainly a valuable source of knowledge, little attention has been paid to the role of employees as a source of new ideas and a liaison between the company and its final users [99]. Furthermore, the intense attention paid to communities has resulted in scant attention to the role of individual users not belonging to communities. Exploring this role could provide fascinating insights into how single final users-company daily interactions work regardless of the role of communities, for example, in the context of the selling points [100]. In this regard: could a practice-based innovation approach to NPD be an effective method to find users to involve in the NPD process beyond the online communities [101]?

In respect of who should be involved to achieve a better co-creation performance, lead users may provide a valuable contribution [74]. However, the rising importance of users with an emergent nature re-open the debate about who should be involved [84]. Promising research avenues need to investigate the psychological facets of users' emergent nature and its effectiveness in different cultural, social and economic contexts as well as the contribution of different degrees of emergent nature and their combination with other psychological traits of the user. Therefore: under which circumstances should a company select a lead user rather than a user with an "emergent nature"?

Finally, in terms of how to extract information from users effectively and efficiently, most of the research focuses on the development of effective automated tools based on machine and deep learning to extract information from users' online behavior. However, there is a need to investigate the relationship between online idea generation tools, the industry, and company performance. In other words, the following questions need answering: could we extend automated tools to a broad spectrum of industries or are they effective in specific sectors only? Moreover, is the innovation performed in a given industry always reflected in online conversations [81]? Although these tools have gone far beyond simple sentiment analysis, there is still a need to refine data processing algorithms in order to not only determine "the what," but also "the why and how" of users' behavior. 


\subsection{Purple cluster: Supplier involvement in new product}

Even if the purple cluster is the most stable in terms of papers and new research perspectives, there is a still need to clarify better the role of suppliers in fostering the success of breakthrough NPD projects and the related inter-organizational relations aimed at promoting radical innovation [89], [90]. Unpacking the NPD process stages, the following questions become relevant: which are the specific contributions of suppliers to radical innovation in the different phases of product design, testing, and commercialization? Which specific investments should suppliers and buyers make in the different stages of the NPD lifecycle? What specific capabilities should both suppliers and buyers develop for more effective collaboration in radical innovation projects?

Finally, in the intersection between the purple and red clusters, there is a need to better map the industrial, organizational, and cultural contextual factors affecting the effectiveness of the supplierbuyer integration [2]. As a result, additional replication and comparative studies are needed to explore the industry-specific moderators, the cultural issues affecting the relationship between suppliers and buyers, and the organizational characteristics that foster a climate of effective supplier-buyer collaboration in the NPD process.

\section{Conclusion}

In this article, we identify and review the main contributions concerning NPD that the business and management literature has offered over the last ten years (2008-2018) and propose practitioners and scholars with some suggestions for further research to fill the existing gaps. Table 3 summarizes the main topics discussed and the possible future research avenues within each of the five clusters analyzed in our review.

\begin{tabular}{|c|c|c|}
\hline Topics & $\begin{array}{l}\text { Exemplary } \\
\text { references }\end{array}$ & Future Research Avenues \\
\hline \multicolumn{3}{|l|}{ Red cluster } \\
\hline $\begin{array}{l}\text { NPD best practices: rigid, sequential and } \\
\text { hierarchical vs. flexible, unstructured, and open. }\end{array}$ & $\begin{array}{l}{[30],[31]} \\
{[34],[35]}\end{array}$ & \multirow{5}{*}{$\begin{array}{l}\text { - Moving from linear to flexible models; } \\
\text { - The impact of Agile principles in no-software } \\
\text { companies; } \\
\text { - KPIs suitable to measure the impact of flexible } \\
\text { models in the NPD process; } \\
\text { - The impact of "soft" aspects on the NPD process; } \\
\text { - Best practices for the NPD process outside the } \\
\text { context of large companies; } \\
\text { - Servitization of the products and their impact on } \\
\text { NPD. }\end{array}$} \\
\hline $\begin{array}{l}\text { Contextual and contingent factors limiting the } \\
\text { generalizability of linear approaches. }\end{array}$ & $\begin{array}{l}{[29],[32],} \\
{[33]}\end{array}$ & \\
\hline $\begin{array}{l}\text { Integration of NPD processes and structures } \\
\text { within the organization of the company. }\end{array}$ & {$[39],[40]$} & \\
\hline $\begin{array}{l}\text { Contextualizing NPD in specific domains: small } \\
\text { companies, family-owned companies, not for } \\
\text { profit organizations, etc. }\end{array}$ & {$[41]-[44]$} & \\
\hline $\begin{array}{l}\text { New service development as a specific domain of } \\
\text { studies. }\end{array}$ & {$[46]-[49]$} & \\
\hline \multicolumn{3}{|l|}{ Green cluster } \\
\hline $\begin{array}{l}\text { Sharing knowledge within the company and } \\
\text { across functional teams using IT tools. }\end{array}$ & {$[51],[52]$} & \\
\hline
\end{tabular}




\begin{tabular}{|c|c|c|}
\hline $\begin{array}{l}\text { Cross Functional Integration (CFI): organizing } \\
\text { departments and SBUs for a superior NPD } \\
\text { performance (macro-level). }\end{array}$ & {$[53]-[56]$} & \multirow{3}{*}{$\begin{array}{l}\text { - Managing the increasing amount of knowledge } \\
\text { flows between and within departments and teams; } \\
\text { - Storing and selecting the right knowledge for the } \\
\text { cross-functional units; } \\
\text { - Team management best practices for cross- } \\
\text { functional teams; } \\
\text {-"Soft" moderators of CFI performance; } \\
\text { - CFI best practices in different contexts; } \\
\text {-CFI success in NSD. }\end{array}$} \\
\hline $\begin{array}{l}\text { CFI: managing teams and fostering collaboration } \\
\text { between members for a superior NPD } \\
\text { performance (micro-level). }\end{array}$ & [57], & \\
\hline $\begin{array}{l}\text { Knowledge of the market and market orientation } \\
\text { for successful product launch and development. }\end{array}$ & {$[59$} & \\
\hline \multicolumn{3}{|l|}{ Blue cluster } \\
\hline Dynamic $\mathrm{Ca}$ & $\begin{array}{l}{[10],[11]} \\
{[61]}\end{array}$ & \multirow{3}{*}{$\begin{array}{l}\text { - Further exploration of NPD as an independent } \\
\text { dynamic capability; } \\
\text { - Extended best practices for partners selections in } \\
\text { trans-national and turmoil contexts; } \\
\text { - Best practices for selecting between various form } \\
\text { of collaboration, openness, public and private } \\
\text { partners; } \\
\text { - The intersection between strategy and CFI. }\end{array}$} \\
\hline $\begin{array}{l}\text { Strategic Alliances and Coopetition for a } \\
\text { successful NPD process: managing partners, } \\
\text { sharing knowledge, and organizing an effective } \\
\text { collaboration. }\end{array}$ & $\begin{array}{l}{[8],[9]} \\
{[62]-[65]}\end{array}$ & \\
\hline $\begin{array}{l}\text { Open innovation and the NPD process: positive } \\
\text { and negative outcomes of the company's } \\
\text { openness. }\end{array}$ & & \\
\hline \multicolumn{3}{|l|}{ Yellow cluster } \\
\hline $\begin{array}{l}\text { Lead users and user communities: a critical look } \\
\text { of their role in NPD and idea generation } \\
\text { processes. }\end{array}$ & $\begin{array}{l}{[13]} \\
{[71]} \\
{[77]}\end{array}$ & \multirow{3}{*}{$\begin{array}{l}\text { - Looking for the right users to be involved in the } \\
\text { co-creation process; } \\
\text { - Looking for alternatives to online communities } \\
\text { and focusing on a comprehensive set of users; } \\
\text { - When selecting between lead users and users with } \\
\text { an "emergent nature"? } \\
\text { - Contextualizing the automated tools considering } \\
\text { the industry where they are used. }\end{array}$} \\
\hline $\begin{array}{l}\text { Automated machine learning tools to screen, } \\
\text { capture, and classify ideas and needs from online } \\
\text { users. }\end{array}$ & {$[78$} & \\
\hline $\begin{array}{l}\text { Developing new services through usage: users' } \\
\text { contribution to NSD and testing. }\end{array}$ & {$[\varepsilon$} & \\
\hline \multicolumn{3}{|l|}{ Purple cluster } \\
\hline The critical role of sup! & {$[-],[00]$} & \multirow{2}{*}{$\begin{array}{l}\text { - Exploring the stages of the NPD process where } \\
\text { suppliers play a critical role; } \\
\text { - How to foster the suppliers' collaboration for } \\
\text { radical innovation. }\end{array}$} \\
\hline $\begin{array}{l}\text { Managing the knowledge flows to and from } \\
\text { suppliers and the role of suppliers in developing } \\
\text { radical and incremental innovation. }\end{array}$ & $\begin{array}{l}{[87],[89]} \\
{[90]}\end{array}$ & \\
\hline
\end{tabular}

Table 3 - Main topics discussed and future research avenues

We focused on topics directly related to the management field, such as the development of best practices to manage NPD, the management of knowledge required to create new products, the NPD process's role in the business strategy domain, as well as end-user and supplier involvement in the process of designing and testing new products. The main limitation of our study is that specific literature gaps have not been addressed due to the limited available space. However, given the size of the field, we picked the most relevant and impactful areas of research, highlighted the major unsolved issues, and suggested possible approaches to tackling these. Our intention is and was to offer scholars useful insights for their future contributions to the topic of NPD. 


\section{References}

[1] H. Ernst, "Success factors of new product development: A review of the empirical literature," Int. J. Manag. Rev., vol. 4, no. 1, pp. 1-40, 2002.

[2] T. E. Johnsen, "Supplier involvement in new product development and innovation: Taking stock and looking to the future," J. Purch. Supply Manag., vol. 15, no. 3, pp. 187-197, 2009.

[3] A. L. Page and G. R. Schirr, "Growth and development of a body of knowledge: 16 years of new product development research, 1989-2004," J. Prod. Innov. Manag., vol. 25, no. 3, pp. 233-248, 2008.

[4] A. L. Page, "Assessing new product development practices and performance: Establishing crucial norms," J. Prod. Innov. Manag., vol. 10, no. 4, pp. 273-290, 1993.

[5] A. Griffin, "PDMA research on new product development practices: Updating trends and benchmarking best practices," J. Prod. Innov. Manag., vol. 14, no. 6, pp. 429-458, 1997.

[6] G. Barczak, A. Griffin, and K. B. Kahn, "PERSPECTIVE: Trends and Drivers of Success in NPD Practices: Results of the 2003 PDMA Best Practices Study,” J. Prod. Innov. Manag., vol. 26, no. 1, pp. 3-23, 2009.

[7] K. B. Kahn, G. Barczak, J. Nicholas, A. Ledwith, and H. Perks, "An Examination of New Product Development Best Practice,” J. Prod. Innov. Manag., vol. 29, no. 2, pp. 180-192, Mar. 2012.

[8] E. (Er) Fang, "The Effect of Strategic Alliance Knowledge Complementarity on New Product Innovativeness in China," Organ. Sci., vol. 22, no. 1, pp. 158-172, 2011.

[9] E. (Er) Fang, J. Lee, and Z. Yang, "The Timing of Codevelopment Alliances in New Product Development Processes: Returns for Upstream and Downstream Partners,” J. Mark., vol. 79, no. 1, pp. 64-82, 2015.

[10] P. A. Pavlou and O. A. El Sawy, "Understanding the Elusive Black Box of Dynamic Capabilities," Decis. Sci., vol. 42, no. 1, pp. 239-273, Feb. 2011.

[11] D. S. Bruni and G. Verona, "Dynamic Marketing Capabilities in Science-based Firms: an Exploratory Investigation of the Pharmaceutical Industry,” Br. J. Manag., vol. 20, no. SI, pp. S101-S117, Mar. 2009.

[12] W. D. Hoyer, R. Chandy, M. Dorotic, M. Krafft, and S. S. Singh, "Consumer Cocreation in New Product Development," J. Serv. Res., vol. 13, no. 3, pp. 283-296, 2010.

[13] W. Chang and S. A. Taylor, "The Effectiveness of Customer Participation in New Product Development: A Meta-Analysis,” J. Mark., vol. 80, no. 1, pp. 47-64, 2016.

[14] J. Fueller, K. Matzler, and M. Hoppe, "Brand community members as a source of innovation," J. Prod. Innov. Manag., vol. 25, no. 6, pp. 608-619, Nov. 2008.

[15] G. Marzi, A. Caputo, E. Garces, and M. Dabić, “A Three Decade Mixed-Method Bibliometric Investigation of the IEEE Transactions on Engineering Management," IEEE Trans. Eng. Manag., vol. 67, no. 1, pp. 4-17, 2020.

[16] R. Todeschini and A. Baccini, Handbook of Bibliometric Indicators: Quantitative Tools for Studying and Evaluating Research. Weinheim: Wiley-VCH, 2016. 
[17] N. J. van Eck and L. Waltman, "Software survey: VOSviewer, a computer program for bibliometric mapping," Scientometrics, vol. 84, no. 2, pp. 523-538, 2010.

[18] N. J. Van Eck, L. Waltman, R. Dekker, and J. Van Den Berg, "A comparison of two techniques for bibliometric mapping: Multidimensional scaling and VOS," J. Am. Soc. Inf. Sci. Technol., vol. 61, no. 12, pp. 2405-2416, 2010.

[19] M. F. Manesh, M. Pellegrini, G. Marzi, and M. Dabic, "Knowledge Management in the Fourth Industrial Revolution: Mapping the Literature and Scoping Future Avenues," IEEE Trans. Eng. Manag., pp. 1-12, 2020.

[20] Y. Ding, R. Rousseau, and D. Wolfram, Measuring Scholarly Impact. Springer, 2014.

[21] M. Mura, M. Longo, P. Micheli, and D. Bolzani, "The Evolution of Sustainability Measurement Research,” Int. J. Manag. Rev., vol. 20, no. 3, pp. 661-695, 2018.

[22] K. W. Boyack and R. Klavans, "Co-citation analysis, bibliographic coupling, and direct citation: Which citation approach represents the research front most accurately?," J. Am. Soc. Inf. Sci. Technol., vol. 61, no. 12, pp. 2389-2404, 2010.

[23] N. J. van Eck and L. Waltman, "VOS: A New Method for Visualizing Similarities Between Objects," in Advances in data analysis, Springer, 2007, pp. 299-306.

[24] P. Smart, D. Tranfield, and D. Denyer, "Towards a methodology for developing evidenceinformed management knowledge by means of systematic review," Br. J. Manag., vol. 14, no. 3, pp. 207-222, 2003.

[25] D. Campagnolo and A. Camuffo, "The concept of modularity in management studies: a literature review," Int. J. Manag. Rev., vol. 12, no. 3, pp. 259-283, 2010.

[26] D. Ravasi and I. Stigliani, "Product design: a review and research agenda for management studies," Int. J. Manag. Rev., vol. 14, no. 4, pp. 464-488, 2012.

[27] B. Kogut and U. Zander, "Knowledge of the Firm, Combinative Capabilities, and the Replication of Technology," Organ. Sci., vol. 3, no. 3, pp. 383-397, 1992.

[28] R. G. Cooper, "Stage-gate systems: a new tool for managing new products," Bus. Horiz., vol. 33, no. 3, pp. 44-54, 1990.

[29] R. Sethi and Z. Iqbal, "Stage-Gate controls, learning failure, and adverse effect on novel new products," J. Mark., vol. 72, no. 1, pp. 118-134, 2008.

[30] R. G. Cooper and A. F. Sommer, "From Experience: The Agile-Stage-Gate Hybrid Model: A Promising New Approach and a New Research Opportunity," J. Prod. Innov. Manag., vol. 33, no. 5, pp. 513-526, 2016.

[31] R. G. Cooper, "Agile-Stage-Gate Hybrids The Next Stage for Product Development," Res. Manag., vol. 59, no. 1, pp. 21-29, 2016.

[32] J. Grönlund, D. R. Sjödin, and J. Frishammar, "Open Innovation and the Stage-Gate Process: A Revised Model for New Product Development," Calif. Manage. Rev., vol. 52, no. 3, pp. 106-131, 2010.

[33] M. S. Salerno, L. A. D. V. Gomes, D. O. Da Silva, R. B. Bagno, and S. L. T. U. Freitas, "Innovation processes: Which process for which project?," Technovation, vol. 35, pp. 59-70, 
2015.

[34] R. G. Cooper and S. J. Edgett, "Maximizing productivity in product innovation," Res. Manag., vol. 51, no. 2, pp. 47-58, 2008.

[35] A. F. Sommer, C. Hedegaard, I. Dukovska-Popovska, and K. Steger-Jensen, "Improved Product Development Performance through Agile/Stage-Gate Hybrids The Next-Generation Stage-Gate Process?," Res. Manag., vol. 58, no. 1, pp. 36-46, 2015.

[36] B. P. Nepal, O. P. Yadav, and R. Solanki, "Improving the NPD Process by Applying Lean Principles: A Case Study," EMJ-ENGINEERING Manag. J., vol. 23, no. 1, SI, p. 52+, Mar. 2011.

[37] N. R. Sangwa and K. S. Sangwan, "Development of an integrated performance measurement framework for lean organizations," J. Manuf. Technol. Manag., vol. 29, no. 1, pp. 41-84, 2018.

[38] C. Moorman and A. S. Miner, "The impact of organizational memory on new product performance and creativity,” J. Mark. Res., vol. 34, no. 1, pp. 91-106, 1997.

[39] D. R. Chang and H. Cho, "Organizational memory influences new product success," J. Bus. Res., vol. 61, no. 1, pp. 13-23, 2008.

[40] C. Salvato and C. Rerup, "Routine Regulation: Balancing Conflicting Goals in Organizational Routines," Adm. Sci. Q., vol. 63, no. 1, pp. 170-209, Mar. 2018.

[41] A. De Massis, J. Kotlar, F. Frattini, J. J. Chrisman, and M. Nordqvist, "Family Governance at Work: Organizing for New Product Development in Family SMEs," Fam. Bus. Rev., vol. 29, no. 2, pp. 189-213, 2016.

[42] A. Ledwith and M. O’Dwyer, "Market Orientation, NPD Performance, and Organizational Performance in Small Firms," J. Prod. Innov. Manag., vol. 26, no. 6, pp. 652-661, Nov. 2009.

[43] N. E. Coviello and R. M. Joseph, "Creating Major Innovations with Customers: Insights from Small and Young Technology Firms,” J. Mark., vol. 76, no. 6, pp. 87-104, Nov. 2012.

[44] H. Berends, M. Jelinek, I. Reymen, and R. Stultiens, "Product Innovation Processes in Small Firms: Combining Entrepreneurial Effectuation and Managerial Causation," J. Prod. Innov. Manag., vol. 31, no. 3, pp. 616-635, 2014.

[45] C. Raddats, C. Kowalkowski, O. Benedettini, J. Burton, and H. Gebauer, "Servitization: A contemporary thematic review of four major research streams," Ind. Mark. Manag., Apr. 2019.

[46] D. Kindstrom and C. Kowalkowski, "Development of industrial service offerings: a process framework,” J. Serv. Manag., vol. 20, no. 2, pp. 156-172, 2009.

[47] C. A. Voss and J. Hsuan, "Service Architecture and Modularity\{*\}," Decis. Sci., vol. 40, no. 3, pp. 541-569, 2009.

[48] J. Z. Raja, D. Bourne, K. Goffin, M. Cakkol, and V. Martinez, "Achieving Customer Satisfaction through Integrated Products and Services: An Exploratory Study,” J. Prod. Innov. Manag., vol. 30, no. 6, pp. 1128-1144, Nov. 2013.

[49] W. G. Biemans, A. Griffin, and R. K. Moenaert, "Perspective: New Service Development: How the Field Developed, Its Current Status and Recommendations for Moving the Field Forward," J. Prod. Innov. Manag., vol. 33, no. 4, pp. 382-397, 2016. 
[50] R. M. Grant, “Toward a knowledge-based theory of the firm," Strateg. Manag. J., vol. 17, no. Winter Special Issue, pp. 109-122, 1996.

[51] S. S. Durmusoglu and G. Barczak, "The use of information technology tools in new product development phases: Analysis of effects on new product innovativeness, quality, and market performance," Ind. Mark. Manag., vol. 40, no. 2, SI, pp. 321-330, Feb. 2011.

[52] T. Mauerhoefer, S. M. Strese, and M. Brettel, "The Impact of Information Technology on New Product Development Performance," J. Prod. Innov. Manag., vol. 34, no. 6, pp. 719-738, Nov. 2017.

[53] H. Ernst, W. D. Hoyer, and C. Ruebsaamen, "Sales, Marketing, and Research-andDevelopment Cooperation Across New Product Development Stages: Implications for Success," J. Mark., vol. 74, no. 5, pp. 80-92, 2010.

[54] L. C. Troy, T. Hirunyawipada, and A. K. Paswan, "Cross-functional integration and new product success: An empirical investigation of the findings," J. Mark., vol. 72, no. 6, pp. 132146, Nov. 2008.

[55] M. Brettel, F. Heinemann, A. Engelen, and S. Neubauer, "Cross-functional integration of $\mathrm{R} \& \mathrm{D}$, marketing, and manufacturing in radical and incremental product innovations and its effects on project effectiveness and efficiency," J. Prod. Innov. Manag., vol. 28, no. 2, pp. 251-269, Mar. 2011.

[56] R. Calantone and G. Rubera, "When Should RD\&E and Marketing Collaborate? The Moderating Role of Exploration-Exploitation and Environmental Uncertainty," J. Prod. Innov. Manag., vol. 29, no. 1, pp. 144-157, 2012.

[57] C. Nakata and S. Im, "Spurring cross-functional integration for higher new product performance: A group effectiveness perspective," J. Prod. Innov. Manag., vol. 27, no. 4, pp. 554-571, 2010.

[58] L. Bstieler and M. Hemmert, "Increasing Learning and Time Efficiency in Interorganizational New Product Development Teams," J. Prod. Innov. Manag., vol. 27, no. 4, pp. 485-499, 2010.

[59] S. N. Ramaswami, R. K. Srivastava, and M. Bhargava, "Market-based capabilities and financial performance of firms: insights into marketing's contribution to firm value," J. Acad. Mark. Sci., vol. 37, no. 2, pp. 97-116, 2009.

[60] M. Augusto and F. Coelho, "Market orientation and new-to-the-world products: Exploring the moderating effects of innovativeness, competitive strength, and environmental forces," Ind. Mark. Manag., vol. 38, no. 1, pp. 94-108, 2009.

[61] O. Schilke, "On the contingent value of dynamic capabilities for competitive advantage: The nonlinear moderating effect of environmental dynamism," Strateg. Manag. J., vol. 35, no. 2, pp. 179-203, Feb. 2014.

[62] C. Haeussler, H. Patzelt, and S. A. Zahra, "Strategic alliances and product development in high technology new firms: The moderating effect of technological capabilities," J. Bus. Ventur., vol. 27, no. 2, pp. 217-233, Mar. 2012.

[63] B. Weber and S. Heidenreich, "When and with whom to cooperate? Investigating effects of 
cooperation stage and type on innovation capabilities and success," Long Range Plann., vol. 51, no. 2, pp. 334-350, Apr. 2018.

[64] R. B. Bouncken, V. Fredrich, P. Ritala, and S. Kraus, "Coopetition in New Product Development Alliances: Advantages and Tensions for Incremental and Radical Innovation," Br. J. Manag., vol. 29, no. 3, pp. 391-410, 2018.

[65] H. Hoang and F. T. Rothaermel, "LEVERAGING INTERNAL AND EXTERNAL EXPERIENCE: EXPLORATION, EXPLOITATION, AND R\&D PROJECT PERFORMANCE,” Strateg. Manag. J., vol. 31, no. 7, pp. 734-758, 2010.

[66] J. H. Love, S. Roper, and P. Vahter, "LEARNING FROM OPENNESS: THE DYNAMICS OF BREADTH IN EXTERNAL INNOVATION LINKAGES,” Strateg. Manag. J., vol. 35, no. 11, pp. 1703-1716, Nov. 2014.

[67] M. P. Knudsen and T. B. Mortensen, "Some immediate - but negative - effects of openness on product development performance," TECHNOVATION, vol. 31, no. 1, SI, pp. 54-64, 2011.

[68] T. O. Salge, T. Farchi, M. I. Barrett, and S. Dopson, "When Does Search Openness Really Matter? A Contingency Study of Health-Care Innovation Projects," J. Prod. Innov. Manag., vol. 30, no. 4, pp. 659-676, 2013.

[69] E. von Hippel, "Lead Users: A Source of Novel Product Concepts," Manage. Sci., vol. 32, no. 7, pp. 791-805, 1986.

[70] E. von Hippel, "Democratizing innovation: The evolving phenomenon of user innovation," $J$. für Betriebswirtschaft, vol. 55, no. 1, pp. 63-78, 2005.

[71] E. von Hippel, S. Ogawa, and J. P. J. de Jong, "The Age of the Consumer-Innovator," MIT Sloan Manag. Rev., vol. 53, no. 1, pp. 27-35, 2011.

[72] M. Schreier and R. Pruegl, "Extending lead-user theory: Antecedents and consequences of consumers' lead userness," J. Prod. Innov. Manag., vol. 25, no. 4, pp. 331-346, 2008.

[73] C. Hienerth and C. Lettl, "Exploring How Peer Communities Enable Lead User Innovations to Become Standard Equipment in the Industry: Community Pull Effects," J. Prod. Innov. Manag., vol. 28, no. 1, pp. 175-195, Nov. 2011.

[74] M. K. Poetz and M. Schreier, "The Value of Crowdsourcing: Can Users Really Compete with Professionals in Generating New Product Ideas?," J. Prod. Innov. Manag., vol. 29, no. 2, pp. 245-256, Mar. 2012.

[75] C. Fuchs and M. Schreier, "Customer Empowerment in New Product Development," J. Prod. Innov. Manag., vol. 28, no. 1, pp. 17-32, 2011.

[76] C. Fuchs, E. Prandelli, and M. Schreier, "The Psychological Effects of Empowerment Strategies on Consumers' Product Demand," J. Mark., vol. 74, no. 1, pp. 65-79, 2010.

[77] C. Hienerth, C. Lettl, and P. Keinz, "Synergies among producer firms, lead users, and user communities: The case of the LEGO producer-user ecosystem," J. Prod. Innov. Manag., vol. 31, no. 4, pp. 848-866, 2014.

[78] T. Kohler, K. Matzler, and J. Fueller, "Avatar-based innovation: Using virtual worlds for realworld innovation," TECHNOVATION, vol. 29, no. 6-7, pp. 395-407, 2009. 
[79] S. Hoornaert, M. Ballings, E. C. Malthouse, and D. den Poel, "Identifying New Product Ideas: Waiting for the Wisdom of the Crowd or Screening Ideas in Real Time," J. Prod. Innov. Manag., vol. 34, no. 5, pp. 580-597, 2017.

[80] T. Y. Lee and E. T. Bradlow, “Automated Marketing Research Using Online Customer Reviews," J. Mark. Res., vol. 48, no. 5, pp. 881-894, 2011.

[81] K. Christensen, S. Norskov, L. Frederiksen, and J. Scholderer, "In Search of New Product Ideas: Identifying Ideas in Online Communities by Machine Learning and Text Mining," Creat. Innov. Manag., vol. 26, no. 1, pp. 17-30, Mar. 2017.

[82] P. Kristensson, J. Matthing, and N. Johansson, "Key strategies for the successful involvement of customers in the co-creation of new technology-based services," Int. J. Serv. Ind. Manag., vol. 19, no. 3-4, pp. 474-491, 2008.

[83] A. Ordanini and A. Parasuraman, "Service Innovation Viewed Through a Service-Dominant Logic Lens: A Conceptual Framework and Empirical Analysis,” J. Serv. Res., vol. 14, no. 1, pp. 3-23, Feb. 2011.

[84] D. L. Hoffman, P. K. Kopalle, and T. P. Novak, "The 'Right' Consumers for Better Concepts: Identifying Consumers High in Emergent Nature to Develop New Product Concepts," J. Mark. Res., vol. 47, no. 5, pp. 854-865, 2010.

[85] G. L. Ragatz, R. B. Handfield, and K. J. Petersen, "Benefits associated with supplier integration into new product development under conditions of technology uncertainty," J. Bus. Res., vol. 55, no. 5, pp. 389-400, 2002.

[86] M. Sjoerdsma and A. J. van Weele, "Managing supplier relationships in a new product development context," J. Purch. Supply Manag., vol. 21, no. 3, pp. 192-203, 2015.

[87] A. A. Mishra and R. Shah, "In union lies strength: Collaborative competence in new product development and its performance effects," J. Oper. Manag., vol. 27, no. 4, pp. 324-338, 2009.

[88] B. Lawson, D. Krause, and A. Potter, "Improving Supplier New Product Development Performance: The Role of Supplier Development," J. Prod. Innov. Manag., vol. 32, no. 5, pp. 777-792, 2015.

[89] P. D. Cousins, B. Lawson, K. J. Petersen, and R. B. Handfield, "Breakthrough Scanning, Supplier Knowledge Exchange, and New Product Development Performance,” J. Prod. Innov. Manag., vol. 28, no. 6, SI, pp. 930-942, Nov. 2011.

[90] M. Song and C. A. Di Benedetto, "Supplier's involvement and success of radical new product development in new ventures," J. Oper. Manag., vol. 26, no. 1, pp. 1-22, 2008.

[91] E. C. Conforto et al., "Be Agile be Adopted by Industries Other than software development?," Proj. Manag. J., vol. 45, no. July, pp. 21-34, 2014.

[92] R. G. Cooper and A. F. Sommer, "The Agile-Stage-Gate Hybrid Model: A Promising New Approach and a New Research Opportunity," J. Prod. Innov. Manag., vol. 33, no. 5, pp. 513526, Sep. 2016.

[93] P. Kettunen, "Adopting key lessons from agile manufacturing to agile software product development-A comparative study," TECHNOVATION, vol. 29, no. 6-7, pp. 408-422, 2009. 
[94] M. Bianchi, G. Marzi, and M. Guerini, “Agile, Stage-Gate and their combination: Exploring how they relate to performance in software development," J. Bus. Res., vol. 110, pp. 538-553, May 2020.

[95] D. A. Reis, A. L. Fleury, and M. M. de Carvalho, "Toward a Recursive Stage-Based Framework for Supporting Startup Business Initiation: An Exploratory Study With Entrepreneurs," IEEE Trans. Eng. Manag., pp. 1-15, 2019.

[96] H. Evanschitzky, M. Eisend, R. J. Calantone, and Y. Jiang, "Success factors of product innovation: An updated meta-analysis," J. Prod. Innov. Manag., vol. 29, pp. 21-37, 2012.

[97] N. Nishino, T. Takenaka, and H. Takahashi, "Manufacturer's strategy in a sharing economy," CIRP Ann. - Manuf. Technol., vol. 66, no. 1, pp. 409-412, 2017.

[98] J. Gesing, D. Antons, E. P. Piening, M. Rese, and T. O. Salge, “Joining Forces or Going It Alone? On the Interplay among External Collaboration Partner Types, Interfirm Governance Modes, and Internal R\&D,” J. Prod. Innov. Manag., vol. 32, no. 3, pp. 424-440, 2015.

[99] C. Wadell, J. Bjork, and M. Magnusson, "How do R\&D employees use their social networks to acquire user information?," J. Knowl. Manag., vol. 18, no. 5, SI, pp. 919-936, 2014.

[100] A. Arvidsson and A. Caliandro, "Brand Public," J. Consum. Res., vol. 42, no. 5, pp. 727-748, 2016.

[101] D. Dougherty, “Organizing Practices in Services: Capturing Practice-Based Knowledge for Innovation," Strateg. Organ., vol. 2, no. 1, pp. 35-64, 2004. 


\section{IEEE Copyright Policies}

\section{General Policies}

In order to maximize the value of IEEE publications to authors, users and the IEEE, the following IEEE copyright policies shall be applied throughout the IEEE:

1. IEEE shall serve and protect the interests of its authors and their employers.

2. All technical, educational and professional publications of the IEEE, except newsletters, but including Society and Technical Council Newsletters, are required to be copyrighted by the IEEE.

3. Copyright shall be held by the IEEE and not any of its organizational units.

4. The Intellectual Property Rights Office is responsible for the administration of all IEEE copyright matters under these policies and the procedures which shall be specified in the PSPB Operations Manual. This includes obtaining the copyright registration, handling reprint and republication requests, maintaining copyright records, and administering fees when appropriate. The Intellectual Property Rights Office may, at its discretion, delegate some or all of its copyright implementation responsibilities to other IEEE departments if they have significant publishing activity, subject to procedures approved by a member of the IEEE staff, as designated by the Executive Director.

5. Third-Party Rights to Reuse IEEE-Copyrighted Material. Licenses and permissions to use IEEE copyrighted material (abstracts, full text, etc.) for commercial or other non-IEEE related purposes may be granted under terms approved by the IEEE Publication Services and Products Board.

6. Fees for the reuse of IEEE material are appropriate for contributing to the cost of original publication, especially where the reuse involves the republication of material, or any commercial uses.

7. Prior to publication by the IEEE, all authors or their employers shall transfer to the IEEE in writing any copyright they hold for their individual papers. Such transfer shall be a necessary requirement for publication, except for material in the public domain or which is reprinted with permission from a copyrighted publication.

8. In return for the transfer of authors' rights, the IEEE shall grant authors and their employers' permission to make copies and otherwise reuse the material under terms approved by the Board of Directors which shall be specified in the PSPB Operations Manual.

9. After IEEE accepts the work for publication and the copyright has been transferred, changes or 
revisions to the work shall not be made without further review and approval.

10. For jointly sponsored conferences, which might require special copyright arrangements, those arrangements shall be made in accordance with the procedures which shall be specified in the PSPB Operations Manual.

11. Copyrighting Electronic Information shall follow the electronic information dissemination procedures, which shall be specified in the PSPB Operations Manual.

12. The PSPB or its authorized designee shall consider the allowance of any exceptions to these Copyright policies.

\section{A. General principles of IEEE copyright policies and procedures}

1. Enhancing the accessibility, distribution and use of information is a major objective of the IEEE publication program, limited only by the requirements of viability and professional propriety.

2. To meet this objective and control the use of its good name, the IEEE is obligated to secure copyright ownership of the material it publishes.

3. In exercising its rights under copyright, the IEEE recognizes that it is acting in part to serve and protect the interests of its authors and their employers.

4. Fees for the reuse of IEEE material are appropriate for contributing to the cost of original publication, especially where the reuse involves a license to copy, or allows resale, or is of a magnitude that would tend to reduce subscription or other sales income.

5. Copyright policies shall be consistently applied throughout IEEE.

\section{B. Ownership and rights of IEEE copyrighted material}

1. Copyright is held by IEEE itself and not any of its Organizational Units.

2. All technical, educational and professional publications of the IEEE, except newsletters, but including Society and Technical Council Newsletters and e-Newsletters, are required to be copyrighted by the IEEE.

3. Prior to publication by the IEEE, all authors or their employers shall transfer to the IEEE in writing any copyright they hold for their individual papers. Such transfer shall be a necessary requirement for publication, except for material in the public domain or which is reprinted from a copyrighted publication.

4. In return for the transfer of authors' rights, the IEEE shall grant authors and their employers permission to make copies and otherwise reuse the material under terms approved by the Board of Directors.

5. In the case of jointly sponsored conferences, IEEE recognizes the right of another qualified sponsor to hold the copyright and administer all copyright matters on behalf of the IEEE and its author, provided, however, that such right shall be the subject of a written agreement between IEEE and the qualified sponsor. A conference is not considered a sponsor and may not hold a copyright to 
IEEE material, except in the case of a conference which is incorporated and maintains its own permanent administrative office.

6. Licenses and permissions to copy or republish IEEE material may be granted under terms approved by PSPB.

\section{Implementation of IEEE copyright policy}

1. The Editor or conference publication committee chair shall be responsible for obtaining the written transfer of author rights and for forwarding appropriate confirmations to the Intellectual Property Rights Office. A form for effecting the interchange of rights with the author per Sections 8.1.4.B.3 and 8.1.4.B.4 form shall be supplied by PSPB or its authorized representative. The wording used on the form shall be approved by PSPB or its authorized representative.

2. For journals and conference publications, an appropriate copyright notice shall appear on the first page of each technical contribution to simplify and facilitate reuse of individual articles.

3. Should the need for isolated exceptions to any of the above policies and procedures arise, PSPB or its authorized representative is authorized to deal with them on a case-by-case basis. 